\title{
NUEVAS RESPUESTAS PARA \\ VIEJAS PREGUNTAS
}

Departamento de Educación/UAA

JARED DiAmond, Armas, gérmenes y acero. La sociedad humana y sus destinos, Madrid, Editorial Debate, 1998, 527 págs. (Primera edición en inglés: 1997.)

aret Diamond es un biólogo, experto en estudios sobre la evolución, que ha vivido largas temporadas entre los indígenas de Nueva Guinea, a algunos de los cuales dedica su libro. Durante varias décadas se ha concentrado en sus estudios sobre aves. Además, es profesor de fisiología en la Escuela de Medicina de la Universidad de California en Los Angeles y autor de divulgación científica muy reconocido, gracias a obras como El tercer chimpancé y la que ahora nos ocupa, con la que se hizo merecedor de los premios Burr, de la National Geographic Society y el prestigioso Pulitzer.

¿Qué tiene que hacer una reseña de una obra de divulgación científica, por buena que pueda ser, en una revista académica de ciencias sociales? Para responder esta pregunta conviene prestar atención a otra, que aparece en la portada misma del libro, como continuación del subtítulo: ¿Por qué los pueblos de Eurasia conquistaron, desplazaron o diezmaron a las poblaciones autóctonas de América, Australia y África, y no a la inversa? En el capítulo 3 de la obra, Diamond plantea la pregunta en forma concreta, que resulta más impactante: el 16 de noviembre de 1532 se encontraron en Cajamarca, en el altiplano peruano, el español Francisco Pizarro, al frente de 168 hombres, y el emperador inca Atahualpa, que mandaba unos 80,000; sin gran esfuerzo, los hombres de Pizarro capturaron al inca. ¿Qué hacían Pizarro y sus hombres tan lejos de su tierra? ¿Cómo pudieron conquistar aquel inmenso territorio? ¿Por qué no fue Atahualpa, al frente de 
los suyos, quien viajó a España y capturó a Carlos I de España y v de Alemania?

¿Por qué, como preguntó en 1972 a Diamond un líder nativo de Nueva Guinea, despertando en él la inquietud que lo llevó a preparar durante 25 años su libro, los europeos y los norteamericanos han llegado a tener un tipo de sociedad que produce cantidades enormes de bienes sofisticados, en tanto que las tribus de Nueva Guinea, que hace poco todavía vivían en la edad de piedra, no lo hicieron? En sus palabras, "¿por qué vosotros los blancos desarrollasteis tanto cargamento y lo trajisteis a Nueva Guinea, pero nosotros los negros teníamos tan poco cargamento propio?".

La pregunta de Diamond es la misma que ha preocupado a muchos estudiosos de las sociedades. ¿Cómo explicar el nivel de desarrollo tan distinto de los pueblos del mundo? El interrogante es de actualidad ante las asimetrías de los actuales procesos de globalización de la economía mundial, entre los que el TLC de América del Norte es un caso destacado.

Además de las explicaciones en términos de superioridad o inferioridad de raza, únicas en el pasado y todavía muy influyentes, las que tratan de evitar el sesgo racial suelen ser insuficientes. Diamond lo plantea así: podemos decir que los europeos, apoyados en miles de años de historia escrita, habían desarrollado naves capaces de cruzar el Atlántico, tenían la ventaja de armas de fuego, espadas de acero y caballos, además de que transmitieron a los indígenas enfermedades para las que no tenían mecanismos de resistencia. Pero entonces hay que preguntar por qué los fenicios y los griegos, y no los incas, desarrollaron la escritura alfabética; por qué no había caballos en Perú y por qué los españoles eran inmunes a los microbios americanos, y no al revés.

Dice Diamond: "Hacia 1500, al iniciarse la expansión colonial europea por el mundo, los pueblos de los distintos continéntes presentaban ya grandes diferencias en cuanto a tecnología y organización política. Gran parte de Europa, Asia y el norte de África albergaban estados o imperios que poseían metales, algunos de ellos en el umbral de la industrialización... los aztecas y los incas gobernaban imperios que disponían de útiles de piedra. Algunas partes del África subsahariana estaban divididas en pequeños estados o jefaturas equipadas con útiles de hierro. La mayoría de los pueblos restantes... vivían en tribus agrícolas o incluso en hordas de cazadores-recolectores que utilizaban herramientas de piedra. Naturalmente, estas diferencias tecnológicas y políticas existentes hacia 1500 fueron la 
causa inmediata de las desigualdades del mundo moderno. Los imperios que disponían de armas de acero pudieron conquistar o exterminar a las tribus que tenían armas de piedra. ¿Cómo, sin embargo, llegó el mundo a ser como era en 1500 ?"

En la presentación del libro, el autor se pregunta: ¿por qué no florecieron el capitalismo en el México nativo, el mercantilismo en el África al sur del Sahara, la ciencia en China, la tecnología avanzada en la Norteamérica india o los microbios más agresivos en Australia? Y continúa: si respondemos invocando factores culturales relativos a la idiosincrasia de ciertos pueblos, por ejemplo, la supuesta barrera que el confucianismo representó para el avance de la ciencia en China, frente al estímulo del pensamiento griego y la tradición judeocristiana en el occidente de Eurasia, entonces seguimos eludiendo la necesidad de explicaciones últimas: ¿por qué en China se desarrollaron tradiciones como el confucianismo y en el occidente de Eurasia otras como las de la ética judeocristiana? Además, estaremos ignorando el hecho de que la China de Confucio estaba más avanzada tecnológicamente que el occidente de Eurasia hasta alrededor del año 1400 de nuestra era.

A lo largo de 19 capítulos y 500 fascinantes páginas, Diamond desarrolla un argumento complejo y lo apuntala con innumerables datos derivados de diversas disciplinas, incluyendo por supuesto a la historia, pero también a la antropología, la biología evolutiva, la genética, la historia de la ciencia y la tecnología, la lingǘstica, etc.

Los factores inmediatos de la desigualdad contemporánea, en juego desde el siglo XVI, se resumen en la tecnología (barcos de altura, armas de fuego, espadas de acero), animales como los caballos, enfermedades epidémicas, la complejidad de la organización política y la presencia o ausencia de la escritura. Por ello el título de la obra: armas, gérmenes $y$ acero.

A partir de estas variables, Diamond inicia su marcha retrospectiva, buscando explicarse la aparición de sociedades con población numerosa, sedentarias y estratificadas, frente a otras con escasa población, nómadas y con organización social simple; sigue analizando las diferencias que llevan a la aparición o no de excedentes alimenticios, que pueden ser almacenados; se remonta a la domesticación de plantas y animales -aparición de agricultura y ganadería- y analiza la presencia de mayores o menores cantidades de animales y plantas susceptibles de domesticación en diversas regiones del planeta, así como la facilidad o dificultad de 
la propagación de especies según que el eje principal de un continente se extienda de este a oeste o de norte a sur.

Se puede discrepar de muchas de las opiniones particulares que contiene la obra de Diamond, y seguramente los avances de la investigación desecharán muchas de ellas, sustituyéndolas por otras mejores. Pero el sentido general de la obra parece muy sólido: el desarrollo de muchas disciplinas está aportando volúmenes de información de dimensiones que no podían imaginarse hace muy poco tiempo que pueden relacionarse, complementarse e integrarse en formas también novedosas. La forma en que la genética, la lingüística o la etnobotánica pueden enriquecer las perspectivas de la historia o la antropología puede constituir una revelación para muchos estudiosos de las ciencias sociales.
Tal vez como reacción frente a explicaciones globales, de inspiración ideológica y escaso sustento empírico, que por mucho tiempo dominaron el campo de las ciencias sociales, los investigadores contemporáneas de la sociología, la historia o la economía por igual, tienden a ver con desconfianza las explicaciones globales, y a dedicar su atención a objetos de estudio mucho más modestos, del tipo que designa la expresión "micro". Esta actitud es en principio muy sana, pero tiene el riesgo de que los árboles no dejen apreciar las dimensiones del bosque.

Por ello puede entenderse que se reseñe en esta revista la obra de Diamond: quienes se dedican a la investigación en ciencias sociales podrán extraer valiosas lecciones de ella.

Además, cualquier lector podrá disfrutar enormemente con su lectura. 